\title{
Molecular cytogenetic analyses of hTERC (3q26) and MYC (8q24) genes amplifications in correlation with oncogenic human papillomavirus infection in Czech patients with cervical intraepithelial neoplasia and cervical carcinomas
}

\author{
P. KUGLIK ${ }^{1,3}$, K. KASIKOVA ${ }^{1,3}$, J. SMETANA ${ }^{1,3, *}$, V. VALLOVA ${ }^{1,3}$, A. LASTUVKOVA ${ }^{1}$, L. MOUKOVA ${ }^{2}$, M. CVANOVA ${ }^{4}$, L. BROZOVA ${ }^{4}$
}

${ }^{1}$ Masaryk University, Institute of Experimental Biology, Laboratory of Molecular Cytogenetics, Brno, Czech Republic; ${ }^{2}$ Masaryk Memorial Cancer Institute, Department of Gynecological Oncology, Brno, Czech Republic; ${ }^{3}$ Department of Medical Genetics, University Hospital, Brno, Czech Republic; ${ }^{4}$ Institute of Biostatistics and Analyses, Faculty of Medicine and Faculty of Science, Masaryk University, Brno, Czech Republic

*Correspondence: smetty@mail.muni.cz

Received March 25, 2014 / Accepted May 19, 2014

It is known that cervical cancer develop from precancerous intraepithelial neoplasia (CIN) which is characterized by series of genetic abnormalities. The progression of CIN to cervical carcinoma has been associated especially with the genomic integration of oncogenic human papilloma virus (HPV) and gain of the human telomerase RNA gene hTERC (3q26) and MYC (8q24).

In this study, cytology specimens of cervical intraepithelial neoplasia and cervical carcinoma from 74 Czech women were analyzed using the triple-color Cervical FISH Probe Kit designed for identification of HPV infected cells and copy number aberration of the $h T E R C$ and MYC genes. HPV-positivity exhibited $70 \%$ of patients with premalignant lesions (CIN I - CIN III, carcinoma in situ), chromosomal changes were found in $53.3 \%$ of cases - MYC amplification had 33.3\% of women with CIN I - CIN III and 50\% with carcinoma in situ. Amplification of $h$ TERC was detected in $16.7 \%$ of patient with CIN I, in $50 \%$ with CIN II, in 58.3\% with CIN III and in 66.7\% with carcinoma in situ. Based on HPV-positivity and the occurrence of chromosomal aberrations, patients were divided into high-, intermediate- and low-risk group.

Among women with cervical carcinomas, HPV infection was detected in $90.1 \%$ of specimens and chromosomal aberrations were found in $87.5 \%$ of samples. Amplification of MYC gene was detected in $25 \%$ and $h T E R C$ gene in $62.5 \%$ of patients. According to the histopathological grade of tumors, MYC gene amplification occurred more frequently in specimens of spinocellular carcinoma than adenocarcinoma $(\mathrm{p}=0.029)$. We found no association between the frequency of cytogenetic lesions and the incidence of lymphangiogenesis or lymph node metastases in cervical carcinoma patients. Simultaneous $h T E R C$ and MYC genes amplification was significantly more frequent in samples of cervical carcinomas than in premalignant lesions $(\mathrm{p}=0.008)$.

In a cohort of 26 patients with cervical carcinoma we used oligo-based GGH+SNP microarray technique for the high resolution mapping of copy number changes of $h T E R C$ and $M Y C$ genes. We found that recurrent gain of genetic material in chromosome 3q26 area carrying hTERC gene of size $43.6 \mathrm{Mb}$ between 3q25.1-3qter and duplication of 3q were the most common genomic identifications of amplified gene. In MYC locus array-CGH profiling identified duplication of $8 \mathrm{q}$ and trisomy 8 as frequent genomic changes.

Our work confirmed that in cervical carcinoma gains of $h T E R C$ and MYC genes are specific genomic changes associated with developing of malignant phenotype. We also showed that in premalignant stages HPV-FISH assay can be used as an effective diagnostic procedure to identify patients carrying highly risking HPV infection and chromosomal aberrations associated with this malignancy.

Key words: cervical cancer, cervical dysplasia, HPV infection, hTERC amplification, MYC amplification, FISH, array-CGH

Cervical carcinoma is one of the most common malignant diseases in women with an estimated 528,000 new cases in 2012 worldwide. Mortality varies between the different regions of the world, with rates ranging from less than 2 per 100,000 in Western Asia, Western Europe and Australia/New Zealand to more than 20 per 100,000 in Melanesia, Middle and Eastern Africa [1]. Most cases (85-90\%) of cervical carcinomas are squamous cell carcinomas, the second largest group is ad- 
enocarcinoma (10-15\%) coming from glandular epithelium, affecting younger women and having worse prognosis. The development of cervical cancer is preceded by cytological changes of cervical cells called cervical intraepithelial neoplasia (CIN). Cervical cytopathology is the routine method for characterization of cells in cervical samples. In mild dysplasia (CIN I) changes occur in low third of epithelial cells; in moderate to marked dysplasia (CIN II), defect of maturation and nucleocytoplasmic ratio changes with numerous mitosis are detected in two thirds of epithelial cells. Defect of maturation with numerous atypical mitoses in the entire width of epithelium is found in severe dysplasia to carcinoma in situ (CIN III).

It is well known that the human papillomavirus (HPV) infection plays an initial role in the development of cervical lesions [2]. However, the high-grade lesions (CIN II - III) and cervical cancer are developed only in a part of infected patients despite the high incidence of HPV infection in dysplastic samples. Therefore, the infection alone is not able to activate the malignant transformation. Genetic abnormalities, the deregulation of oncogenes and tumor suppressor genes, are essential in progress of cancerogenesis [3,4]. In malignant and premalignant lesions and cervical carcinoma cell lines, specific chromosomal changes were observed.

The most frequent alteration, detected in approximately $70 \%$ of cervical carcinomas, is amplification of chromosome $3 q[5,6]$. The region $3 q 26$ contains a RNA subunit of human telomerase RNA gene $h T E R C$. Many studies show the rate of $h T E R C$ amplification correlates with development of CIN lesions to carcinoma and thus it can be a predictive factor of malignant transformation and progression [7-10].

Other frequently observed change is an amplification of protooncogene MYC (8q24). This gene encodes transcription factor that plays a role in cell cycle progression, proliferation, apoptosis and cellular transformation. Expression of MYC in cells of invasive carcinomas is increased more than in CIN cells [11]. According to published data, the amplification of both genes, $h T E R C$ and $M Y C$ can serve as an important marker of chromosomal instability of cervical cells infected with HPV [12] predicting the progression of precancerous cervical lesions into higher stages or into invasive cervical carcinomas.

The application of molecular cytogenetic techniques to study genomic alterations as a biomarker for progression during uterine tumorigenesis provided the rationale for the development of fluorescence in situ hybridization (FISH) assay as a cytogenetic diagnostic tool for the direct detection of HPV infected cells and alterations of selected genes in cytology specimens. Particularly, triple-color Vysis Cervical FISH Probe Kit was designed to identify HPV infected cells and determine copy number changes of the $h T E R C$ and MYC gene via FISH (HPV-FISH) $[12,13]$.

In this study, cytologic specimens of 74 women from Dept. of Gynecological Oncology of Masaryk Memorial Cancer Institute Brno with histologically confirmed diagnosis of CIN I-CIN III, carcinoma in situ or cervical cancers were analyzed using HPV-FISH assay. We evaluated HPV infection/hTERC/MYC gene amplification in routinely collected cytology samples (PAP smears) and compared the cytogenetic findings with the histological diagnose and clinical outcome. We also set the prognostic risk for each patient according to recommended settings. In addition, 26 cervical carcinomas samples were subjected to array-CGH analysis using Agilent SurePrint G3 Human CGH+SNP 4x180K microarray for the high resolution mapping of copy number changes of $h T E R C$ and $M Y C$ genes.

\section{Patients and methods}

Samples. Cervical specimens were obtained from Dept. of Gynecological Oncology, Masaryk Memorial Cancer Institute (MMCI) Brno, Czech Republic. Totally 74 patients were included in the study (median age 40.5 years, range 22 - 86 years). The distribution of patients based on histology classification and the clinical characteristics are presented in Table 1. All samples were obtained only after the patients signed the informed consent approved by the Ethical committee of the MMCI. Patients with cervical carcinomas after surgical procedures and any adjuvant treatment were monitored in regular intervals according to oncogynecological guidelines. The follow-up period was $6-36$ months, and overall survival was not reached as all patients in our cohort are still alive without any sign of tumor recurrence.

PAP smears were prepared according to standard procedure. Slides were fixed in methanol for 20 minutes at $4{ }^{\circ} \mathrm{C}$ and in methanol with acetic acid (3:1) for another 20 minutes at $4{ }^{\circ} \mathrm{C}$. Slides were dried at room temperature and then stored at $-20^{\circ} \mathrm{C}$ before hybridization.

Probe description. To identify human papillomavirus (HPV) infected cells and determine copy number of the chromosomal regions 3q26 (hTERC) and 8q24 (MYC) via fluorescence in situ hybridization (HPV-FISH), Vysis Cervical FISH Probe Kit was used. This kit enables the identification of high-risk HPV types $(16,18,31,33,35,39,45,51,52,53$, $56,58,59,66,68)$ using biotin labeling and tyramide signal amplification assay. Detection of copy number alteration of hTERC and MYC genes is done using standard FISH. The $h T E R C$ probe is labeled with SpectrumGold fluorescent label and covers approximately $495 \mathrm{~kb}$ region; the $M Y C$ probe is labeled with SpectrumRed fluorescent label and covers approximately $821 \mathrm{~kb}$ region.

Slide pretreatment and hybridization. Slide pretreatment and FISH were performed according to the manufacturer's protocols (Abbott-Vysis). Briefly, slides were soaked in 2x SSC at $73{ }^{\circ} \mathrm{C}$ for 2 minutes and incubated in pepsin $(0.5 \mathrm{mg} / \mathrm{ml}$ in $10 \mathrm{mmol} / \mathrm{l} \mathrm{HCl}$ ) at $37^{\circ} \mathrm{C}$ for 10 minutes. Slides were soaked in 1x PBS at RT for 5 minutes, fixed in 1\% neutral-buffered formalin at RT for 5 minutes and soaked in $1 \mathrm{x}$ PBS at RT for 5 minutes. Slides were dehydrated in ethanol series of 70,80 and $96 \%$ for 1 minute and air dried. The probe mixture $(10 \mu \mathrm{l})$ was applied on the slides; samples were codenatured at $72{ }^{\circ} \mathrm{C}$ 
Table 1. Clinical characteristics of the patients' cohort

\begin{tabular}{|c|c|c|}
\hline $\mathbf{N}(\%)$ & & Without pathology $(\mathrm{N}=12)^{1}$ \\
\hline \multirow[t]{3}{*}{ Histology } & inflammation & $3(25.0 \%)$ \\
\hline & precancerosis in $\mathrm{CE}^{2}$ & $9(75.0 \%)$ \\
\hline & & Precancerosis $(\mathrm{N}=30)^{1}$ \\
\hline \multirow[t]{5}{*}{ Histology } & CIN I & $6(20.0 \%)$ \\
\hline & CIN II & $6(20.0 \%)$ \\
\hline & CIN III & $12(40.0 \%)$ \\
\hline & Ca in situ & $6(20.0 \%)$ \\
\hline & & Carcinoma $(\mathrm{N}=32)^{1}$ \\
\hline \multirow[t]{2}{*}{ Histology } & spinocellular carcinoma & $25(78.1 \%)$ \\
\hline & adenocarcinoma & $7(21.9 \%)$ \\
\hline \multirow[t]{9}{*}{ Stage } & IA1 & $2(6.3 \%)$ \\
\hline & IA2 & $2(6.3 \%)$ \\
\hline & IB1 & $17(53.3 \%)$ \\
\hline & IB2 & $3(9.4 \%)$ \\
\hline & IIA & 0 \\
\hline & IIB & 0 \\
\hline & IIIA & 0 \\
\hline & IIIB & $6(18.7 \%)$ \\
\hline & IVA & $2(6.3 \%)$ \\
\hline \multirow[t]{8}{*}{ T classification } & T1a1 & $2(6.3 \%)$ \\
\hline & T1a2 & $2(6.3 \%)$ \\
\hline & T1b1 & $21(65,5 \%)$ \\
\hline & T1b2 & $4(12.5 \%)$ \\
\hline & $\mathrm{T} 2 \mathrm{a}$ & 0 \\
\hline & $\mathrm{T} 2 \mathrm{~b}$ & $1(3.1 \%)$ \\
\hline & $\mathrm{T} 3 \mathrm{~b}$ & 0 \\
\hline & $\mathrm{T} 4 \mathrm{a}$ & $2(6.3 \%)$ \\
\hline \multirow[t]{10}{*}{ Metastasis } & LN not affected & $21(77.8 \%)$ \\
\hline & MTS 1 LN & $1(3.7 \%)$ \\
\hline & MTS 2 LN & $1(3.7 \%)$ \\
\hline & MTS 3 LN & $1(3.7 \%)$ \\
\hline & MTS 4 LN & $1(3.7 \%)$ \\
\hline & MTS 7 LN & $1(3.7 \%)$ \\
\hline & MTS $13 \mathrm{LN}$ & $1(3.7 \%)$ \\
\hline & unclassified & $5(15.6 \%)$ \\
\hline & negative & $21(77.8 \%)$ \\
\hline & positive & $6(22.2 \%)$ \\
\hline \multirow{3}{*}{$\begin{array}{l}\text { Grade of } \\
\text { carcinoma }\end{array}$} & G1 & $4(12.5 \%)$ \\
\hline & G2 & $12(37.5 \%)$ \\
\hline & G3 & $16(50.0 \%)$ \\
\hline \multirow[t]{2}{*}{$\begin{array}{l}\text { Lymphangioin- } \\
\text { vasion }\end{array}$} & negative & $19(59.4 \%)$ \\
\hline & positive & $13(40.6 \%)$ \\
\hline
\end{tabular}

${ }^{1}$ described by absolute and relative frequencies - N (\%)

${ }^{2} \mathrm{CE}$...cytological examination

for 2 minutes and hybridized at $37^{\circ} \mathrm{C}$ overnight. After hybridization, slides were washed in $2 \mathrm{x}$ SSC at $48^{\circ} \mathrm{C}$ for 2 minutes and in $2 \mathrm{x}$ SSC at RT for 1 minute.

HPV detection using tyramide signal amplification assay. Detection of the biotin-labeled HPV probes was performed using Alexa Fluor 488 TSA (tyramide signal amplification) kit (Invitrogen) according to Cervical FISH Probe Kit directions. Slides were incubated in $3 \% \mathrm{H}_{2} \mathrm{O}_{2}$ at RT for 30 minutes to block endogenous peroxidase activity and soaked in $1 \mathrm{x}$ PBS at RT for 5 minutes. Before application of streptavidin-HRP (SA-HRP) conjugate (diluted 1:100 in blocking reagent), slides were incubated with $1 \%$ blocking reagent in PBS (both incubations were performed in a humified chamber at $37^{\circ} \mathrm{C}$ for 25 minutes). After washing the slides three times in $1 \mathrm{x}$ PBS at $37^{\circ} \mathrm{C}$ for 5 minutes, the biotin-labeled HPV probe-SA-HRP complex was visualized by incubation with Alexa Fluor 488 labeled tyramide (1:100 dilution) for 10 minutes at RT. The slides were washed three times in $1 \mathrm{x} P B S$ at $37^{\circ} \mathrm{C}$ for 5 minutes and nuclear counterstain DAPI was applied.

Slide analysis. Slides were analyzed under the fluorescent microscope BX-61 (Olympus) using DAPI, green, gold and red single bandpass filter sets. The 1300D CCD camera (Vds Vosskühler, Osnabrück, Germany) was used for image acquisition. Image analysis was performed using the LUCIA-KARYO/ FISH software (Laboratory Imaging, Prague, Czech Republic). The entire hybridized surface area was analyzed in all cases. HPV staining was visualized with a green filter and localized to the nucleus as confirmed by DAPI staining. HPV staining pattern was classified as diffuse, mixed and punctate (Figure 1 ) as described previously $[12,13]$. The sample was considered positive for HPV infection if at least one HPV-positive cell was found.

All HPV-positive cells and their pattern were recorded and number of $h T E R C$ and MYC signals was determined for each HPV-positive cell. According to the manufacturer's instruction (Abbott Molecular, Inc., Des Plaines, IL), the case was considered positive for chromosomal aberration if 4 or more HPV-positive cells demonstrated copy number gain (more than 2 fluorescent signals) of at least one chromosome locus ( $h T E R C$ or MYC). Otherwise, case was considered HPV positive but chromosome negative.

In the absence of HPV-positive cells, slide was evaluated for the presence of cells with amplified $h T E R C$ and/or MYC genes. The case was considered positive for chromosomal aberration if more than $5.8 \%$ (cut-off value from negative controls at the 95\% confidence limit) of cells demonstrated copy number gain (more than 2 fluorescent signals) of at least one chromosome locus ( $h T E R C$ or MYC). Otherwise, the case was considered HPV and chromosome negative. According to the HPV and chromosomal findings, patients were classified to the risk group (Figure 2).

Patients with HPV-negative cells and no copy number changes of $h T E R C$ and $M Y C$ were classified as low risk. Women who had HPV-positive cells without chromosomal aberration belonged to intermedium risk group and patients with HPVpositive cells and amplification of $h T E R C$ or MYC genes were classified as high risk.

Array-comparative genomic hybridization. Tumor samples were stored at $-70^{\circ} \mathrm{C}$ until DNA isolation. Genomic DNA 
A

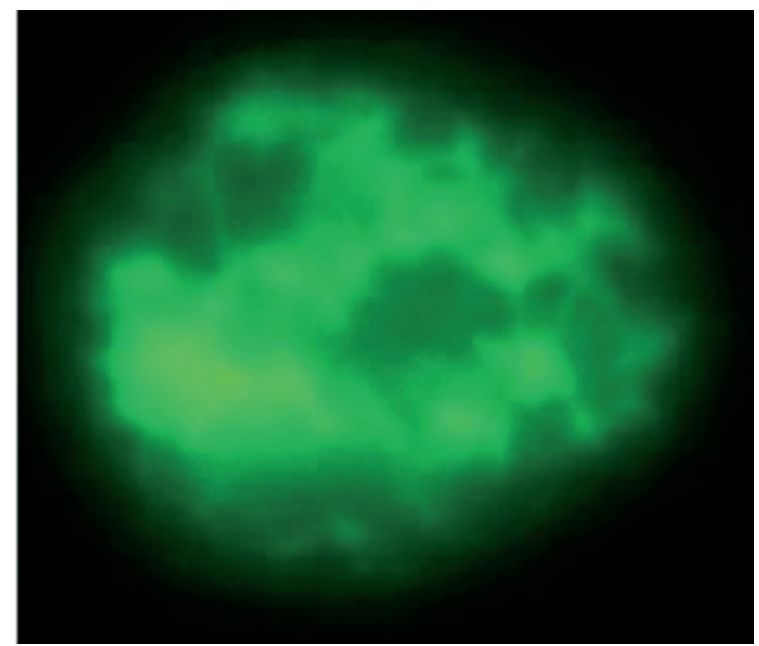

Figure 1. HPV staining pattern using Vysis Cervical FISH Probe Kit

A) Diffuse staining pattern: episomal HPV state

B) Punctate staining pattern: integrated HPV state
B

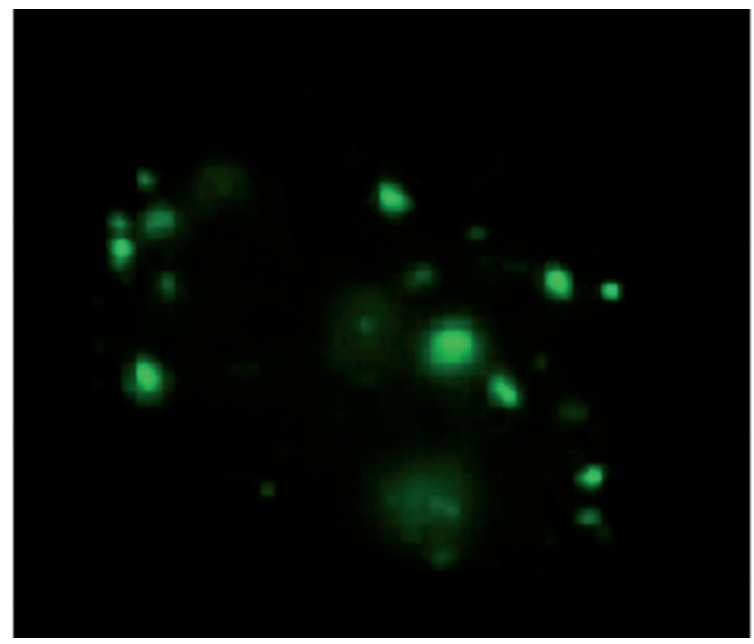

\section{A}

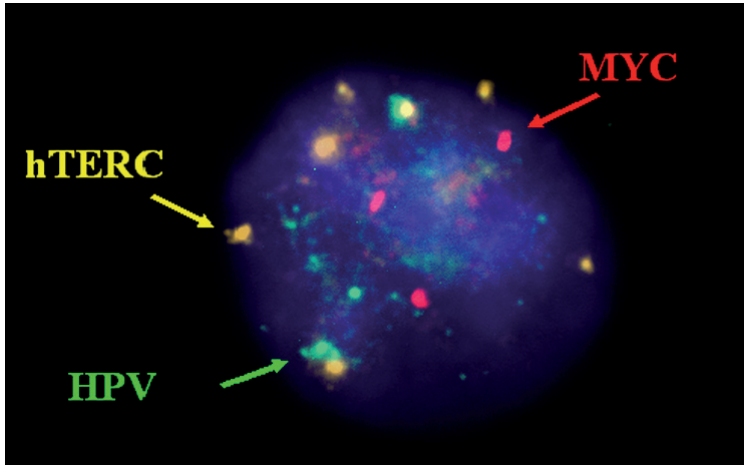

C

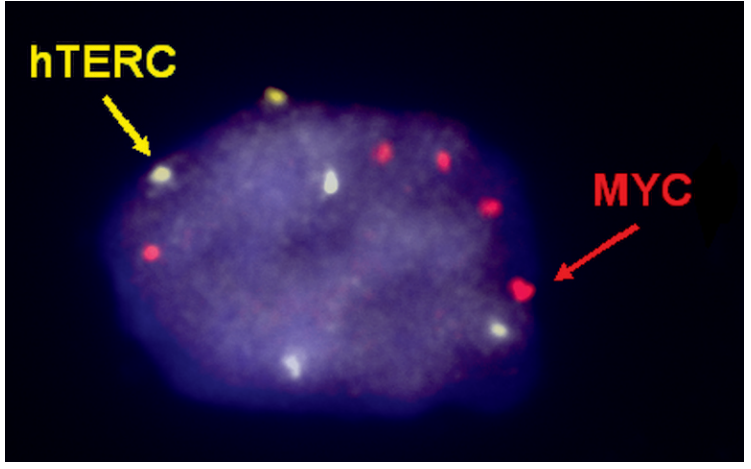

B

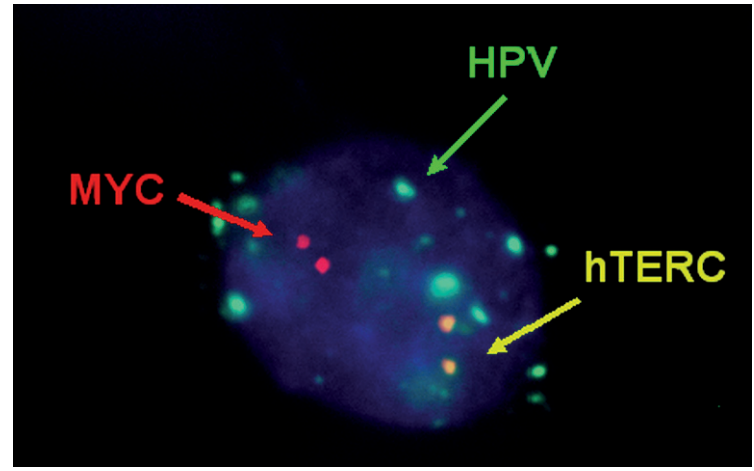

D

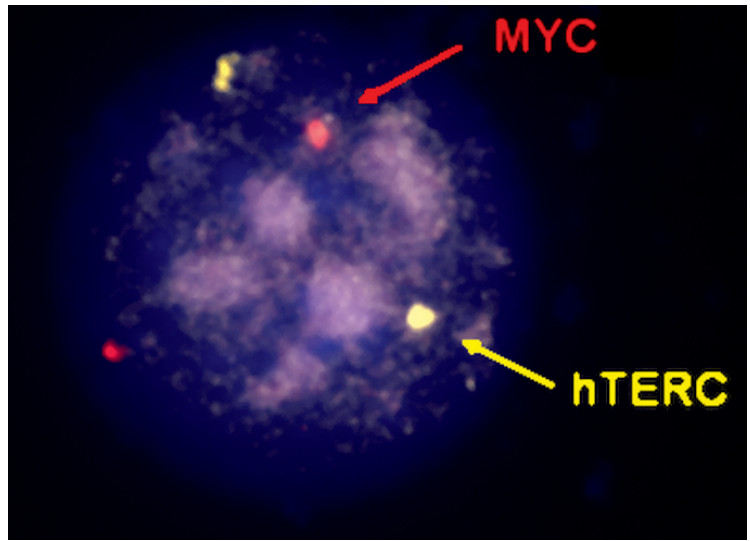

Figure 2. Representative images of HPV staining (green) and chromosome probes for hTERC (yellow) and MYC (red) signals observed after HPV-FISH assay.

A) HPV-positive cell (green spots) with amplification of $h T E R C$ (more than 2 yellow spots) and MYC (more than 2 red spots) genes - classified as HIGH RISK

B) HPV-positive cell (green spots) without copy number changes of $h T E R C$ (only 2 yellow spots) and MYC (only 2 red spots) genes - classified as INTERMEDIUM RISK

C) HPV-negative cell (no green spots) with amplification of $h T E R C$ (more than 2 yellow spots) and MYC (more than 2 red spots) genes - classified as HIGH RISK

D) HPV-negative cell (no green spots) without copy number changes of $h T E R C$ (only 2 yellow spots - one is split) and MYC (only 2 red spots) - classified as LOW RISK 
Table 2. The summary of HPV positivity and the amplifications of the hTERC and MYC genes in 72 women with a cervical precancerous and cervical carcinomas analyzed by HPV-FISH technique

\begin{tabular}{|c|c|c|c|}
\hline $\mathbf{N}(\%)$ & $\begin{array}{l}\text { Without } \\
\text { pathology } \\
(\mathrm{N}=12)\end{array}$ & $\begin{array}{l}\text { precancerous } \\
\qquad(\mathrm{N}=30)\end{array}$ & $\begin{array}{c}\text { Carcinoma } \\
(\mathrm{N}=\mathbf{3 2})\end{array}$ \\
\hline \multicolumn{4}{|l|}{ HPV by FISH } \\
\hline negative & $2(16.7 \%)$ & $9(30.0 \%)$ & $3(9.4 \%)$ \\
\hline positive & $10(83.3 \%)$ & $21(70.0 \%)$ & $29(90.6 \%)$ \\
\hline \multicolumn{4}{|c|}{ Positive HPV by FISH } \\
\hline CIN I & - & $3(50.0 \%) / 6$ & - \\
\hline CIN II & - & $3(50.0 \%) / 6$ & - \\
\hline CIN III & - & $10(83.3 \%) / 12$ & - \\
\hline Ca in situ & - & $5(83.3 \%) / 6$ & - \\
\hline \multicolumn{4}{|c|}{ Amplification total } \\
\hline none & $9(75.0 \%)$ & $14(46.7 \%)$ & $4(12.5 \%)$ \\
\hline MYC & 0 & $1(3.3 \%)$ & 0 \\
\hline hTERC & 0 & $5(16.7 \%)$ & $8(25.0 \%)$ \\
\hline$M Y C$ and $h T E R C$ & $3(25.0 \%)$ & $10(33.3 \%)$ & $20(62.5 \%)$ \\
\hline \multicolumn{4}{|l|}{ Risk groups } \\
\hline Low risk & $2(16.7 \%)$ & $6(20.0 \%)$ & 0 \\
\hline Intermediate risk & $7(58.3 \%)$ & $8(26.7 \%)$ & $4(12.5 \%)$ \\
\hline High risk & $3(25 \%)$ & $16(53.3 \%)$ & $28(87.5 \%)$ \\
\hline
\end{tabular}

(gDNA) for array-CGH experiments was isolated using standard phenol extraction. Simultaneous whole-genome analysis of unbalanced chromosomal changes (CNAs) and copy-neutral regions of loss of heterozygosity $(\mathrm{cnLOH})$ in cervical tumors was done using oligonucleotide-based or SurePrint G3 CGH+SNP Array $180 \mathrm{~K}$ platform (Agilent Technologies, Santa Clara, CA, USA), as described elsewhere. Briefly, $1-1.5 \mu \mathrm{g}$ of reference DNA (Agilent Euro Female) and patient DNA were digested with Alu1 and Rsa1 (Promega, Madison, WI, USA) for 2 hours at $37^{\circ} \mathrm{C}$. Fluorescent labeling was done by the SureTag DNA Labeling Kit (Agilent Technologies). Purified and differentially labeled sample and reference DNA were cohybridized at $65^{\circ} \mathrm{C}$ for 24 hours to the array. Microarrays were scanned with Agilent SureScan C Scanner with $3 \mu \mathrm{m}$ resolution, features were extracted using Feature Extraction software (v11.1) and normalized data were analyzed and visualized by Agilent Genomic Workbench v. 7.0.1.4

Statistical analyses. Fisher's exact test was applied when two categorical variables were compared. Mann-Whitney test was used for testing differences in continuous parameters between groups. Statistical analyses were performed using the software $\mathrm{IBM}^{\circledR} \mathrm{SPSS}^{\bullet}$ Statistics 21.

\section{Results}

Molecular cytogenetic analyses of hTERC (3q26) and MYC (8q24) genes amplifications using HPV-FISH

Patients without pathology. The first group of studied women were twelve patients without pathology, three of them (25\%) had chronic inflammation and nine (75\%) had precancerosis in cytological, not in histological examination. HPV infection was found in 83.3\% (10/12) of samples. Chromosomal aberrations were detected in $25 \%$ (3/12) of patients. In all 3 cases the amplification of both genes MYC and $h T E R C$ together was found (Table 2).

Following HPV positivity and chromosomal alterations, $16.7 \%(2 / 12)$ of patients were classified as low-risk, $58.3 \%$ (7/12) of women as intermediate-risk and 25\% (3/12) of patients were put into high risk group.

Patients with premalignant dysplasia. Based on histological findings, specimens of 6 patients with CIN I, 6 patients with CIN II, 12 patients with CIN III and 6 patients with carcinoma in situ were examined.

HPV-positive cells were found in 70\% (21/30) of women from this subgroup. According to histology, HPV-positive samples were detected in $50 \%$ of patients with CIN I and CIN II, and in $83.3 \%$ of patients with CIN III and with carcinoma in situ (Table 2).

Among thirty patients with precancerosis, copy number changes of MYC and $h T E R C$ genes were found in $53.3 \%(16 / 30)$ of cases. Totally, the amplification of MYC gene occurred in $36.6 \%(11 / 30)$ of women and the amplification of $h T E R C$ gene was detected in $50 \%(15 / 30)$ of patients.

Single amplification of MYC gene was detected in 3.3\% $(1 / 30)$ of woman. Solely amplification of $h T E R C$ gene was detected in $16.7 \%(5 / 30)$ of specimens and the amplification of both genes MYC and $h T E R C$ together was found in $33.3 \%$ $(10 / 30)$ of patients (Table2).

With regards to histological grades, the amplification of MYC gene had $33.3 \%$ of women with CIN I - CIN III and $50 \%$ of women with carcinoma in situ. Amplification of hTERC gene was detected in $16.7 \%$ of patient with CIN I, in $50 \%$ with CIN II, in $58.3 \%$ with CIN III and in $66.7 \%$ of women with carcinoma in situ (Table 3).

According to the HPV and chromosomal findings, the risk assessment was set down $-20 \%$ of patients were categorized as low-risk, $26.7 \%$ of patients as intermediate-risk and $53.3 \%$ of patients as high-risk.

Patients with cervical cancer. Furthermore, the 32 women with cervical cancer were also examined by HPV-FISH and HPV infection was found in 90.1\% (29/32) of samples.

Chromosomal abnormalities were present in $87.5 \%$ $(28 / 32)$ of patients from this subgroup. Amplification of MYC gene occurred in $62.5 \%(20 / 32)$ and amplification of $h T E R C$ gene was detected in $87.5 \%$ (28/32) of patients (Table 2). Totally, no solely amplification of MYC gene was detected, 25\% (8/32) of specimens had single amplification of $h T E R C$ gene and the amplification of both $M Y C$ and $h T E R C$ genes together was noticed in $62.5 \%(20 / 32)$ of patients.

Following HPV-positivity and chromosomal alterations $87.5 \%$ of patients were classified as high-risk and $12.5 \%$ of women as intermediate-risk. No patient with cervical cancer was included in the low-risk category. 
Table 3. Comparison of $h T E R C$ and $M Y C$ amplifications in 30 patients with a cervical precancerous according to histological grade

\begin{tabular}{|c|c|c|c|c|c|}
\hline $\mathrm{N}(\%)$ & $\begin{array}{l}\text { Histology of precancer- } \\
\text { ous }(\mathrm{N}=30)\end{array}$ & & & & \\
\hline & CIN I (N=6) & CIN II (N=6) & CIN III (N=12) & Ca in situ $(N=6)$ & $\mathbf{p}^{1}$ \\
\hline \multicolumn{6}{|l|}{ Amplification } \\
\hline none & $4(66.7 \%)$ & $3(50.0 \%)$ & $5(41.7 \%)$ & $2(33.3 \%)$ & \multirow{4}{*}{0.225} \\
\hline MYC & $1(16.7 \%)$ & 0 & 0 & 0 & \\
\hline hTERC & 0 & $1(16.7 \%)$ & $3(25.0 \%)$ & $1(16.7 \%)$ & \\
\hline$M Y C$ and $h T E R C$ & $1(16.7 \%)$ & $2(33.3 \%)$ & $4(33.3 \%)$ & $3(50.0 \%)$ & \\
\hline none $M Y C$ & $4(66.7 \%)$ & $4(66.7 \%)$ & $8(66.7 \%)$ & $3(50.0 \%)$ & \multirow{2}{*}{0.663} \\
\hline MYC & $2(33.3 \%)$ & $2(33.3 \%)$ & $4(33.3 \%)$ & $3(50.0 \%)$ & \\
\hline none $h T E R C$ & $5(83.3 \%)$ & $3(50.0 \%)$ & $5(41.7 \%)$ & $2(33.3 \%)$ & \multirow{2}{*}{0.109} \\
\hline hTERC & $1(16.7 \%)$ & $3(50.0 \%)$ & $7(58.3 \%)$ & $4(66.7 \%)$ & \\
\hline \multicolumn{6}{|l|}{ Risk groups } \\
\hline Low risk & $2(33.3 \%)$ & $2(33.3 \%)$ & $1(8.3 \%)$ & $1(16.7 \%)$ & \multirow{3}{*}{0.431} \\
\hline Intermediate risk & $2(33.3 \%)$ & $1(16.7 \%)$ & $4(33.3 \%)$ & $1(16.7 \%)$ & \\
\hline High risk & $2(33.3 \%)$ & $3(50.0 \%)$ & $7(58.3 \%)$ & $4(66.7 \%)$ & \\
\hline
\end{tabular}

${ }^{1} \mathrm{p}$-value of a Kruskal-Wallis test with histology as continuous variable coded as CIN I=0, CIN II=1, CIN III =2, Ca in situ=3

We also analyzed $M Y C$ and $h T E R C$ genes amplifications in relation to standard clinical parameters. According to the histopathological grade of tumors, MYC amplification occurred more frequently in specimens of spinocellular carcinoma $(65.0 \% ; 13 / 20)$ than adenocarcinoma $(35.0 \% ; 7 / 20)$ and this association was statistically significant $(\mathrm{p}=0.029)$ (Table 4$)$. Also a trend between $M Y C$ gene amplification and tumor size was detected - carcinomas in T1b1, T1b2b and T2b stage had gain of MYC more often ( $\mathrm{p}=0.092$ ).

Lymph node space invasion (LVSI) was observed in $40.6 \%$ $(13 / 32)$ of patients with cervical carcinomas.

Amplification of $M Y C$ gene in this subgroup was found in $53.8 \%$ (7/13) of women and amplification of $h T E R C$ gene occurred in $92.8 \%(12 / 13)$ of patients while in patients without LVSI the incidence was $68.4 \%$ (13/19) for MYC gene and $84.2 \%$ $(16 / 19)$ for $h T E R C$ gene amplification. Comparison of MYC and $h T E R C$ genes amplification between LVSI positive and negative cohort showed no statistical significance $(\mathrm{p}=0.434)$.

Similar results were obtained in patients affected with metastases in regional lymph nodes (LNM). We observed amplification of MYC and $h T E R C$ genes in patients with (6) and without (21) LMN (50.0\% vs. $67.0 \% ; 100 \%$ vs. $86 \%$, respectively), however the differences did not meet statistical significance $(\mathrm{p}=0.371)$. Thus, the frequency of amplification was not associated with metastatic behavior.

Comparison of hTERC and MYC genes amplification between patients with premalignant lesions and patients with cervical cancer. Detailed analysis of chromosomal findings in patients with premalignant lesions and cervical cancer showed that simultaneous hTERC and MYC genes amplification was significantly more frequent in samples of cervical carcinomas than in specimens of premalignant lesions ( $62.5 \%$ vs. $33.3 \%$; $\mathrm{p}=0.008)$. Likewise, solely amplification of $h T E R C$ gene was significantly $(\mathrm{p}=0.002)$ more frequently detected in patients with cancer $(87.5 \%)$ than in women with precancerous stage $(50 \%)$. The analysis of risk group distribution (Table 2) revealed that patients with premalignant dysplasia fell within all three groups, while majority of women with cervical cancer belonged to highrisk group (87.5\%; $\mathrm{p}=0.003)$.

Mapping hTERC and MYC genes amplification by High-Density Oligonucleotide Array-CGH. A subset of 26 cervical carcinoma cases was also analyzed using high-density oligonucleotide array-CGH for the detection of $h T E R C$ and $M Y C$ genes amplifications. These arrays were performed to confirm the presence of genetic abnormalities detected by

Table 4. Statistically significant associations of the histology of a carcinoma and the amplification of MYC gene

\begin{tabular}{|c|c|c|c|c|c|c|c|}
\hline & \multicolumn{3}{|c|}{ Amplification total ${ }^{1}$} & \multicolumn{4}{|c|}{ Amplification of $M Y C$ gene $^{1}$} \\
\hline & $\operatorname{non}(\mathrm{N}=4)$ & $h T E R C(\mathrm{~N}=8)$ & $M Y C$ and $h T E R C(\mathrm{~N}=20)$ & $\mathbf{p}^{2}$ & negative $(\mathrm{N}=12)$ & positive $(\mathrm{N}=20)$ & $\mathbf{p}^{2}$ \\
\hline \multicolumn{8}{|l|}{ Histology of carcinoma } \\
\hline spinocellular carcinoma & $4(100.0 \%)$ & $8(100.0 \%)$ & $13(65.0 \%)$ & & $12(100.0 \%)$ & $13(65.0 \%)$ & 0.029 \\
\hline adenocarcinoma & 0 & 0 & $7(35.0 \%)$ & 0.090 & 0 & $7(35.0 \%)$ & 0.029 \\
\hline
\end{tabular}

${ }^{1}$ described by absolute count and relative frequencies $-\mathrm{N}(\%)$

${ }^{2}$ p-value of a Fisher's exact test 


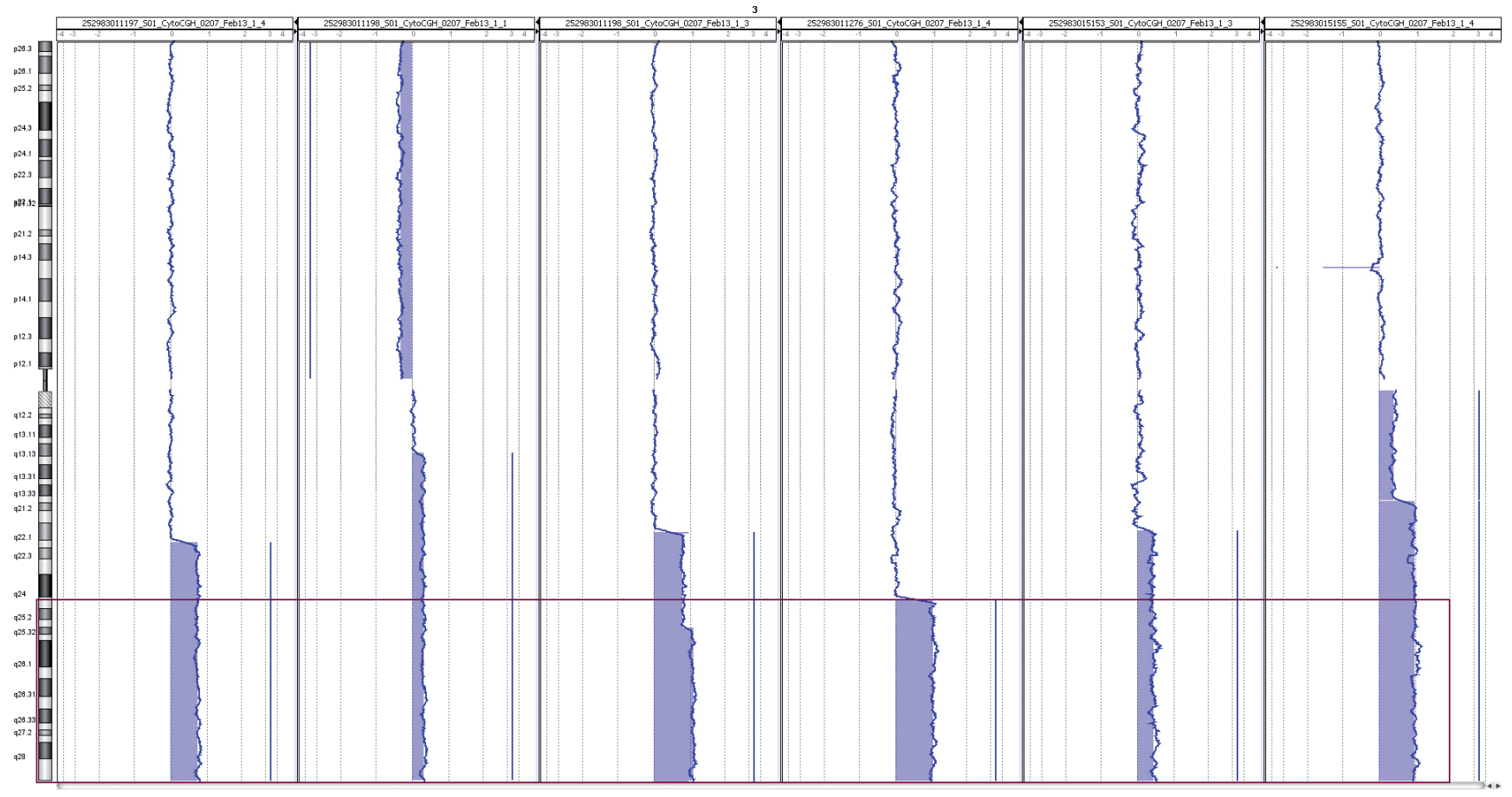

Figure 3. Graphical overview of minimal region of gain (MDR) in chromosome 3q in 6 patients with cervical carcinoma. Highlighted box shows minimally gained region $43.6 \mathrm{Mb}$ of size between 3q25.1-3qter carrying $h T E R C$ locus.

HPV-FISH and to define the size and the character of these genomic changes.

In our dataset, the recurrent gain in chromosome $3 \mathrm{q} 26$ area carrying $h T E R C$ was observed in 50\% (13/26) of samples. In $23.1 \%$ of cases $(6 / 26)$, we found minimal region of genetic material gain (MGR) of $43.6 \mathrm{Mb}$ between 3q25.1-3qter, with amplification ( $>5$ copies) of $h$ TERC loci in $11.6 \%(3 / 26)$ of samples (Figure 3 ). In addition, duplication of whole $3 q$ arm was detected in $19.2 \%$ (5/26) of cases; in 2 cases we observed trisomy of chromosome 3 .

Incidence of genetic material gain in MYC locus (8q24.3) was observed in $15.4 \%(4 / 26)$. In 2 cases we found trisomy of chromosome 8 and 2 cases had gain of whole $8 q$ arm.

\section{Discussion}

Cervical cancer remains the second most common malignancy among women in the Czech Republic with the incidence 19/100000. It is known that the infection of cervical epithelial cells with HPV is necessary but still insufficient for neoplastic progression.

Genetic abnormalities play an important role in tumor transformation etiology. Characteristic marker of malignant tumors is chromosomal instability, either numeric or structural, having prognostic and predictive impact in many tumor sites. In cervical malignant and premalignant lesions and cervical carcinoma cell lines, specific chromosomal changes were repeatedly found, mainly in regions 3q26 (hTERC gene) [14] and 8q24 (MYC gene) [15]. According to published data, $80-90 \%$ of cervical carcinoma cases are characterized by an amplification of human telomerase RNA gene (hTERC) [16]. This specific genetic abnormality was found also in premalignant CIN II/CIN III and is considered as a genetic aberration occurring in early stages of the tumor development with value to predict malignant transformation and progression of the disease $[8,14,17]$.

Another specific genetic abnormality linked to the development of cervical carcinoma is MYC gene amplification. Golijow et al. [15] showed that there is a difference among the number of MYC copies in CIN I, CIN II/CIN III and carcinoma in situ and thus the amplification of MYC gene is not important only in progression of the tumor, but even in the cell transformation during pre-invasive stages.

The principal aim of this study was to optimize the molecular cytogenetic technique, i.e. HPV-FISH assay, originally developed by Sokolova et al. [12] and to evaluate HPV infection/hTERC/MYC genes amplification in routinely collected cytology samples obtained from 74 patients with cervical dysplasia or cervical carcinomas. The Vysis Cervical FISH Probe Kit contains multi-color FISH probes for hTERC (3q26) and MYC (8q24) genes together with an HPV probe cocktail containing $6 \mathrm{HPV}$ types with homology to the majority of high-risk types. In our study, we verified utilization of this kit as a robust tool for subclassification of patients into low-, intermediate- and high risk subgroups and identifying risk of progression from mild and moderate stages to high grade dysplasia. 
Although HPV-positive cells were observed in our study in the group of women without pathology, $75 \%$ (9) patients had no amplification of MYC or $h T E R C$ genes. It suggests that these HPV infected cells will be eventually eliminated by immune system; spontaneous regression comes in about $95 \%$ of HPV infected cells [18]. However, simultaneous amplification of $h T E R C$ and MYC detected in 25\% (3) of women without pathology indicates that patients with high risk can also be in this group. Jiang et al. and Chen et al. $[19,20]$ analyzed hTERC gene in 178 and 164 patients without oncological finding and the amplification of this gene was found in $6.2 \%$ and $9.2 \%$ respectively. Our observed results can be caused by small number of tested women. It is highly possible that these double-positive cells will progress to premalignant lesions. Study of Heselmeyer-Haddad et al. [7] proved that cells with 3q gain are not able to regress spontaneously and they have persistent infection of HPV. Thus, it is necessary to provide regular check-ups of these women and in case of progression to take therapeutic measures.

In the group of patients with premalignant lesions (CIN I - III, carcinoma in situ), the incidence of HPV-positive cells is in correlation with increasing grade of intraepithelial neoplasia. HPV-positive samples were detected in $50 \%$ of patients with CIN I, in $50 \%$ of women with CIN II, in $83.3 \%$ of patients with CIN III and in $83.3 \%$ of women with carcinoma in situ. Positive correlation between histological stage and incidence of $h T E R C$ amplification was also found - amplification of hTERC was detected in $16.7 \%$ of patient with CIN I, in $50 \%$ of women with CIN II, in $58.3 \%$ of patients with CIN III and in $66.7 \%$ of women with carcinoma in situ. This trend was also observed by other teams. Heselmeyer-Haddad et al. [7] found positivity for extra copies of 3q in 7.1\% ( 1 of 15) of CIN I samples, $62.5 \%$ (5 of 8 ) of CIN II samples and 76.4\% (13 of 17) of CIN III samples. Chen et al. [20] observed hTERC amplification in $17.2 \%(5 / 29)$ of CIN I patients, in $76.2 \%$ $(16 / 21)$ CIN II patients and even in $100 \%(22 / 22)$ patients with CIN III. Another two Chinese studies also confirmed that increase of $h T E R C$ amplification was correlated with higher histological grade of premalignant lesions. In large study, Jiang et al. [19] examined specimens of 4851 women with premalignant lesions, positivity of $h T E R C$ gain was detected in $20.8 \%$ of women with CIN I, in $68.6 \%$ patients with CIN II and in $82.4 \%$ women with CIN III. Similarly, in study of Jin et al. [9] amplification of $h$ TERC occurred in $18.2 \%$ (6/33) of CIN I patients, in $66.7 \%$ (6/9) of CIN II patients and in $84.6 \%(22 / 26)$ of CIN III patients.

These findings confirmed that amplification of hTERC gene in patients with precancerous cervical lesions is a strong prognostic marker of progression of the disease and this biomarker should be used in clinical diagnostics as a preventive and routine screening tool.

The MYC gene amplification was detected in patients of all precancerous grades (CIN I - CIN III 33.3\%; carcinoma in situ 50\%). The 8q24 gain confirms the integration of HPV into cell genome because the activation and overexpression of MYC gene start in cells with integrated virus [21]. Chen et al. [10] detected the amplification of MYC gene in $31 \%$ of patients in CIN I grade, in $71.4 \%$ of patients in CIN II grade and in $81.8 \%$ of patients in CIN III grade. In our set, increasing incidence of MYC amplification correlating with higher CIN grade was not proved; one of the possible explanations could be the small number of examined patients.

Using molecular cytogenetic analyses, HPV infection was found in $90.1 \%$ of patients with cervical cancer. Chromosomal change of $M Y C$ gene occurred in $62.5 \%$ and amplification of $h T E R C$ gene was present in $87.5 \%$ of patients from this group. Comparison of $h T E R C$ and MYC genes amplification rates between patients with intraepithelial neoplasia and patients with cervical carcinoma showed significantly higher frequency of these alterations in carcinoma samples.

The amplification of human telomerase RNA gene was shown to be the most frequent aberration in cervical cancer; more than $85 \%$ invasive cervical carcinomas carry this gain [7]. Jiang et al. [19] observed $h T E R C$ amplification in $94.9 \%$ of patients with squamous cell carcinoma, Yin el al. [22] detected this alteration even in $100 \%$ of women with invasive carcinoma of cervix uteri. Other subsequent studies $[9,16,17,20,23]$ also proved gain of $3 \mathrm{q}$ chromosome arm as the most common aberration.

From the clinical view, we tested the diagnostic and prognostic value of MYC and $h T E R C$ genes alterations in cervical cancer patients detected by HPV-FISH.

In our study, MYC gene amplification was found to be significantly more frequent in specimens of spinocellular carcinomas than adenocarcinomas. Similar findings were described by Jin et al. [9] and Chen et al. [10], who studied the role of $M Y C$ protooncogene in origin and progression of cervical carcinomas. Recently, Wright et al. confirmed [24] that spinocellular carcinomas and adenocarcinomas have distinctly different molecular profiles that may explain the observed clinical differences.

A correlation between $M Y C$ gene amplification and tumor size was also detected - our samples of carcinomas in T1b1, T1b2b and T2b stages had the gain of MYC gene more often. However, this correlation needs to be proved on a larger set of patients. Also Abba et al. [25] and Eid et al. [26] found significant correlation between $M Y C$ gene amplification and tumor grading. Lymphovascular space invasion is an important independent prognostic factor in cervical carcinoma diagnosis, and it is in direct correlation with the incidence of lymph node metastases [27,28].

Statistical analysis of our results did not reveal relationship between $h T E R C / M Y C$ genes amplification rate and lymphangioinvasion or presence of metastasis in lymphatic nodes. However, study of Riou et al. [29] found significant relation between MYC overexpression and higher risk of distant metastases and relapse in set of women with early stages of carcinoma. Kim et al. [30] consider MYC gene amplification to be a prognostic factor of DFS (disease-free survival) in patients with operable IB - IIB stage of carcinoma. 
In patients with cervical cancers we need further studies with $h T E R C$ and MYC genes evaluation to confirm that these genetic biomarkers are associated with a more advanced grade or can predict a risk of spread outside primary localization and determine probability of disease recurrence.

Analysis of $h T E R C$ and MYC loci with array-CGH showed that both changes are presented as a part of complex genetic lesions in genome of tumor cells in cervical carcinoma patients. Our results showed that both $h T E R C$ and MYC genes amplifications are mostly part of larger areas gain in chromosome arms, or even whole chromosomes. Amplification of hTERC gene in our cohort was observed most frequently as a minimal region of gain in 3q25 - 3qter in $23.1 \%$ (6/26), while in $19 \%$ $(5 / 26)$ we found gain of whole $3 q$ arm and 2 cases with trisomy of chromosome 3. Similar observations were made by other groups when array-CGH technique was used MRG defined slightly different between 3q24-3q26 [31-33]. This discrepancy can be explained by utilization lower resolution BAC microarrays with combination of FFPF samples. Likewise, incidence of MYC gene amplification was connected with chromosome 8 trisomy ( 2 cases) or whole 8 q gain ( 2 cases).

In conclusion, our results showed that analysis of $h T E R C$ and MYC genes as the specific genetic biomarkers is important and has a great diagnostic and prognostic potential both in patients with cervical precancer and cervical carcinoma. The testing of $h T E R C$ and MYC gene amplification by HPV-FISH in cervical lesions might be a supplementary to cytology screening and HPV test, especially in high-risk patients. Based on HPV infection presence and results of molecular cytogenetic examination we can better specify intraepithelial dysplasia, predict its regression or progression to invasive cancer and choose an appropriate therapeutic procedure.

In patients with cervical cancers we need further studies with $h T E R C$ and MYC genes evaluation to confirm that these genetic biomarkers are associated with a more advanced grade or can predict of risk of spread outside primary localization and determine probability of disease recurrence.

Acknowledgements: This study was supported by research grant projects NT 11089-4/2010 and OPVK CZ.1.07/2.3.00/20.0183

\section{References}

[1] WHO 2012. International Agency for Research on Cancer - GLOBOSCAN 2012 http: //globocan.iarc.fr/Pages/ fact_sheets_cancer.aspx

[2] WALBOOMERS JMM, JACOBS M, MANOS MM, BOSCH FX, KUMMER JA et al. Human papillomavirus is a necessary cause of invasive cervical cancer worldwide. J. Pathol. 1999; 189: 12-19. http://dx.doi.org/10.1002/(SICI)10969896(199909)189:1<12::AID-PATH431>3.0.CO;2-F

[3] YEASMIN S, NAKAYAMA K, RAHMAN MT, RAHMAN M, ISHIKAWA M et al. Expression of nuclear Notch3 in cervical squamous cell carcinomas and its association with adverse clinical outcomes. Gynecol Oncol. 2010; 117: 409-16. http:// dx.doi.org/10.1016/j.ygyno.2010.03.004
[4] MÜNGER K, BALDWIN A, EDWARDS KM, HAYAKAWA $\mathrm{H}$, NGUYEN CL et al. Mechanisms of human papilloma virus-induced oncogenesis. J Virol 2004; 78: 1451-60. http:// dx.doi.org/10.1128/JVI.78.21.11451-11460.2004

[5] HUANG FY, KWOK YK, LAU ET, TANG MH, NG TY et al. Genetic abnormalities and HPV status in cervical and vulvar squamous cell carcinomas. Cancer Genet Cytogenet 2005; 157: 42-48. http://dx.doi.org/10.1016/j.cancergencyto.2004.06.002

[6] KIRCHHOFF M, ROSE H, PETERSEN BL, MAAHR J, GERDES $\mathrm{T}$ et al. Comparative genomic hybridization reveals a recurrent pattern of chromosomal aberrations in severe dysplasia/carcinoma in situ of the cervix and in advancedstage cervical carcinoma. Genes Chromosomes Cancer 1999; 24: 144-50. http://dx.doi.org/10.1002/(SICI)10982264(199902)24:2<144::AID-GCC7 >3.0.CO;2-9

[7] HESELMEYER-HADDAD K, SOMMERFELD K, WHITE NM, CHAUDHRI N, MORRISON LE et al. Genomic amplification of the human telomerase gene (TERC) in Pap smears predicts the development of cervical cancer. Am J Pathol 2005; 166: 1229-1238. http://dx.doi.org/10.1016/ $\underline{\text { S0002-9440(10)62341-3 }}$

[8] HOPMAN AH, THEELEN W, HOMMELBERG PP, KAMPS MA, HERRINGTON CS et al. Genomic integration of oncogenic HPV and gain of the human telomerase gene TERC at 3 q26 are strongly associated events in the progression of uterine cervical dysplasia to invasive cancer. J Pathol. 2006; 210: 412-9. http://dx.doi.org/10.1002/path.2070

[9] JIN Y, LI JP, HE D, TANG LY, ZEE CS et al. Clinical Significance of Human Telomerase RNA Gene (hTERC) Amplification in Cervical Squamous Cell Lesions Detected by Fluorescence in Situ Hybridization. Asian Pac J Cancer Prev. 2011; 12: 1167-71.

[10] CHEN S, YANG Z, ZHANG Y, QIAO Y, CUI B et al. Genomic amplification patterns of human telomerase RNA gene and C-MYC in liquid-based cytological specimens used for the detection of high-grade cervical intraepithelial neoplasia. Diagn Pathol. 2012; 7: 40-52. http://dx.doi.org/10.1186/17461596-7-40

[11] BUSMANIS I. Biomarkers in Carcinoma of the Cervix: Emphasis on Tissue-related Factors and Their Potential Prognostic Factors. Ann Acad Med Singapore 1998; 27: 671-5.

[12] SOKOLOVA I, ALGECIRAS-SCHIMNICH A, SONG M, SITAILO S, POLICHT F et al. Chromosomal biomarkers for detection of human Papillomavirus associated genomic instability in epithelial cells of cervical cytology specimens. J Mol Diagn 2007; 9: 604-611. http://dx.doi.org/10.2353/ jmoldx.2007.070007

[13] ALGECIRAS-SCHIMNICH A, POLICHT F, SITAILO S, SONG M, MORRISON L et al. Evaluation of Quantity and Staining Pattern of Human Papillomavirus (HPV)-Infected Epithelial Cells in Thin-Layer Cervical Specimens Using Optimized HPV-CARD Assay. Cancer Cytopathol 2007; 111: 330-6. http://dx.doi.org/10.1002/cncr.22946

[14] HESELMEYER-HADDAD K, JANZ V, CASTLE PE, CHAUDHRI N, WHITE $\mathrm{N}$ et al. Detection of genomic amplification of the human telomerase gene (TERC) in cyto- 
logic specimen as a genetic test for the diagnosis of cervical dysplasia. Am J Pathol 2003; 163: 1405-16. http://dx.doi. org/10.1016/S0002-9440(10)63498-0

[15] GOLIJOW CD, ABBA MC, MOURÓN SA, GÓMEZ MA, DULOUT FN. C-myc gene amplification detected in preinvasive intraepithelial cervical lesions. Int J Gynecol Cancer 2001; 11: 462-5. http://dx.doi.org/10.1046/j.15251438.2001.01063.X

[16] YANG YC, SHYONG WY, CHANG MS, CHEN YJ, LIN $\mathrm{CH}$ et al. Frequent gain of copy number on the long arm of chromosome 3 in human cervical adenocarcinoma. Cancer Genet Cytogenet 2001; 131: 48-53. http://dx.doi.org/10.1016/ $\underline{\text { S0165-4608(01)00510-6 }}$

[17] ALAMEDA F, ESPINET B, CORZO C, MU-OZ R, BELLOSILLO B et al. 3q26 (hTERC) gain studied by fluorescence in situ hybridization as a persistence-progression indicator in low-grade squamous intraepithelial lesion cases. Hum Pathol 2009; 40: 1474-8. http://dx.doi.org/10.1016/j.humpath.2009.03.013

[18] OSTOR AG, MULVANY N. The pathology of cervical neoplasia. Curr Opin Obstet Gynecol 1996; 8: 69-73.

[19] JIANG J, WEI LH, LI YL, WU RF, XIE X et al. Detection of TERC amplification in cervical epithelial cells for the diagnosis of high-grade cervical lesions and invasive cancer: a multicenter study in China. J Mol Diagn. 2010; 12: 808-17. http:// dx.doi.org/10.2353/jmoldx.2010.100021

[20] CHEN SM, LIN W, LIU X, ZHANG YZ. Significance of human telomerase RNA gene amplification detection for cervical cancer screening. Asian Pac J Cancer Prev 2012; 13: 2063-8. http://dx.doi.org/10.7314/APJCP.2012.13.5.2063

[21] PETER M, ROSTY C, COUTURIER J, RADVANYI F, TESHIMA $\mathrm{H}$ et al. MYC activation associated with the integration of HPV DNA at the MYC locus in genital tumors. Oncogene 2006; 25: 5985-93. http://dx.doi.org/10.1038/ sj.onc. 1209625

[22] YIN G, LI J, ZHU T, ZHAO X. The detection of hTERC amplification using fluorescence in situ hybridization in the diagnosis and prognosis of cervical intraepithelial neoplasia: a case control study. World J Surg Oncol. 2012; 10: 168-173. http://dx.doi.org/10.1186/1477-7819-10-168

[23] CARAWAY NP, KHANNA A, DAWLETT M, GUO M, GUO N et al. Gain of the 3 q26 region in cervicovaginal liquid-based pap preparations is associated with squamous intraepithelial lesions and squamous cell carcinoma. Gynecol Oncol 2008; 110: 37-42. http://dx.doi.org/10.1016/j. ygyno.2008.01.040
[24] WRIGHT AA, HOWIT BE, MEYERS AP, DAHLBERG SE, PALESCANDOLO E et al. Oncogenic mutations in cervical cancer. Cancer 2013; 119: 3776-83 http://dx.doi.org/10.1002/ cncr.28288

[25] ABBA MC, LAGUENS RM, DULOUT FN, GOLIJOW $\mathrm{CD}$. The c-myc activation in cervical carcinomas and HPV 16 infections. Mutat Res. 2004; 557: 151-8. http://dx.doi. org/10.1016/j.mrgentox.2003.10.005

[26] EID MM, NOSSAIR HM, ISMAEL MT, AMIRA G, HOSNEY MM et al. Clinical significance of hTERC and C-Myc genes amplification in a group of Egyptian patients with cancer cervix. Gulf J Oncolog. 2011; 10: 18-26.

[27] CREASMAN WT, KOHLER MF. Is lymph vascular space involvement an independent prognostic factor in early cervical cancer? Gynecol Oncol. 2004; 92: 525-529. http://dx.doi. org/10.1016/j.ygyno.2003.11.020

[28] MARCHIOLE P, BUENERD A, BENCHAIB M, NEZHAT $\mathrm{K}, \mathrm{DARGENT} \mathrm{D}$ et al. Clinical significance of lympho vascular space involvement and lymph node micrometastases in early-stage cervical cancer: a retrospective case-control surgico-pathological study. Gynecol Oncol. 2005; 97: 727-732. http://dx.doi.org/10.1016/j.ygyno.2005.01.004

[29] RIOU GF, BOURHIS J, LE MG. The c-myc proto-oncogene in invasive carcinomas of the uterine cervix: clinical relevance of overexpression in early stages of the cancer. Anticancer Res. 1990; 10(5A): 1225-31.

[30] KIM TJ, LEE A, LEE SJ, LEE WC, LEE KY et al. Prognostic Significance of Amplification of the c-MYC Gene in Surgically Treated Stage IB-IIB Cervical Cancer. Korean J Pathol 2011, 45: 596-603. http://dx.doi.org/10.4132/KoreanJPathol.2011.45.6.596

[31] ALLEN DG, WHITE DJ, HUTCHINS AM, SCURRY JP, TABRIZI SN et al. Progressive genetic aberrations detected by comparative genomic hybridization in squamous cell cervical cancer. Br J Cancer 2000; 83: 1659-1663. http://dx.doi. org/10.1054/bjoc.2000.1509

[32] WILTING SM, DE WILDE J, MEIJER CJ, BERKHOF J, YI Y et al. Integrated genomic and transcriptional profiling identifies chromosomal loci with altered gene expression in cervical cancer. Genes Chromosomes Cancer 2008; 47: 890-905. http:// dx.doi.org/10.1002/gcc.20590

[33] THOMAS LK, BERMEJO JL, VINOKUROVA S, JENSEN K, BIERKENS M. el al. Chromosomal gains and losses in human papillomavirus-associated neoplasia of the lower genital tract - a systematic review and meta-analysis. Eur. J. Cancer 2014; 50: 85-98. http://dx.doi.org/10.1016/j.ejca.2013.08.022 